\section{THE LAND OF THE MARSUPIALS}

Biogeography and Ecology in Australia

Edited by A. Keast, R. L. Crocker and C. S. Christian. (Monographiae Biologicae, Vol. 8.) Pp. iv $+640+18$ plates. (The Hague: Dr. W. Junk, 1959.) 65 guilders.

THE continent of Australia is about the same size as the United States or 25 times the area of the British Isles. Sydney was settled in 1788 , but it was not until about 1825 that other coastal areas began to be developed. The 'gold rushes' brought a great increase of population in the mid-nineteenth century. It was not until a little more than a century ago that the dawn of scholarship came with the establish. ment of the Universities of Sydney and Melbourne.

In the pioneer era, the studies of the infant departments of biology were of necessity concerned largely with the description of local fauna and flora. In later years, however, the pendulum of interest swung remarkably so that the chief studies of a majority of senior academic zoologists were of problems that could be rather more efficiently attacked in London or New York. The wonder, then, is not that Australians know so little about the ecology, biogeography and physiology of their native fauna, but (as is shown by the present volume) that they know so much. It is significant that much of the new zoological knowledge is not due to the efforts of university workers, but to officers of the splendid Commonwealth Scientific and Industrial Research Organization.

"Biogeography and Ecology in Australia" will be valuable not only for ecologists but also as a general reference book for university teachers, senior students and biologists in general. (For example, how many know that there are only 11 fewer eutherians than marsupials in "the land of marsupials" ?) The book brings together much of the available knowledge, as well as enabling us to see where the gaps are. The first essay deals with "The Uniqueness of Australia in Biology" (by F. S. Bodenheimer) and then follow thirty-six chapters on the ecology of primitive aboriginal man, contemporary human ecology, that of the vegetation, the extant chordate classes, some of the major invertebrate groups and other topics. Pleasing evidence that, largely under the impetus of a Swiss and an Englishman, Australians are at last beginning to study the biology of Australian mammals is found in the chapters by Main et al. and Sharman. Among the hitherto unsuspected physiological adaptations of certain pouched mammals is rumination. Delayed implantation, too, has been demonstrated in two species by Sharman and Ealey and others within the past few vears.

A. J. MarshatL

\section{CLIMATIC ATLAS OF THE CZECHOSLOVAK REPUBLIC}

\section{Atlas Podnebi Ceskoslovenské Republiky}

Pp. $42+100$ plates. (Praha: Ustřední Správa Geodesie a Kartografie, 1958.) Cena Kčs. 300.

7 HIS impressive book contains 89 charts of Czechoslovakia on the scale of $1: 10^{6}$ and eleven diagrams. The maps, which measure about $2 \mathrm{ft} .6 \mathrm{in}$. by $1 \mathrm{ft}$. 6 in., are beautifully printed in attractive systems of different colours for areas of different values of the elements concerned. East and West Germany are the only other countries to have produced a climatic atlas with maps of so large a scale.

Detailed descriptions of the contents are given in English, Russian, and French as well as Czech.

The first nine charts give the administrative areas, river basins, soil types, forest regions and climatic regions based on Konček's humidity index for the vegetation period.

Next there are thirty-one temperature charts which give mean monthly and annual isotherms of screen temperature (that is, not reduced to mean sea-level), mean numbers of days of maximum temperature over $25^{\circ} \mathrm{C}$, , of maximum below $-0.1^{\circ} \mathrm{C}$., etc., mean first and last frost days, and the mean duration of various periods such as the one of mean daily temperature $5^{\circ} \mathrm{C}$. or more. The mean temperature of the day is defined as $(7)+(14)+2(21) / 4,(7)$, denoting the temperature at seven hours, etc. In summer this probably gives a rather higher value than the customary British formula of average of maximum and minimum. As charts of mean values they are excellent, but for an area of such variable weather as Central Europe they much need to be supplemented by information on extremes. Extremes are not mentioned anywhere, yet other sources give the following table for Prague in January :

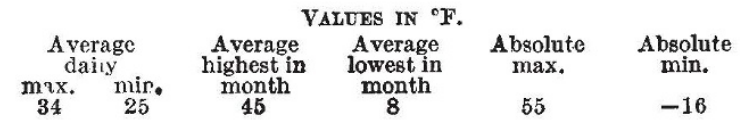

The information outlined on average monthly extremes and absolute extremes is the least information on variability which ought to be included for scientific and economic purposes.

The section on precipitation contains mean monthly and annual amounts, means for the vegetation and winter periods and the mean numbers of days with precipitation exceeding 1 and $10 \mathrm{~mm}$., days of snowfall and snow cover, etc. Next there is a section with maps of wind-roses, averages of relative humidity in July and December, mean cloudiness in September, November and the year, annual numbers of days of fog, sunshine, and thunderstorms. These are standard features of most climatic atlases, but for a country of mixed terrain like this much is lost by giving only annual values of sunshine since it is well known that there is a marked seasonal difference between the relative sunshine distribution in mountains and plains.

Finally, there are twelve phenological charts (mean date of apple-blossoming, harvesting oats, etc.) and eleven charts of seasonal variations of soil tempera. ture. The latter, with examples for a hot summer and a severe winter, are the only sections of the book to give any indication of extrenue values.

The period of the observations used is mainly 1901-1950 but is 1926-1950 for some and 1946-1953 for wind-roses. The preface mentions that it is intended to publish a volume of tables but suggests that this will contain only the data used in drawing the isopleths of the work under review. It is much to bo hoped that the tables will in fact contain some data on extremes of temperature and precipitation if it is not possible to go all the way and provide an airmass climatology similar to that published in 1958 for West Germany (Ber. deutschen Wetterdienstes No. 45. "Zur Klimatologie der Grosswetterlagen", by K. Bürger.)
G. A. BULL 